Marquette University

e-Publications@Marquette

College of Nursing Faculty Research and

Publications

Nursing, College of

$5-1-2016$

Feasibility of Hair Collection for Cortisol Measurement in Population Research on Adolescent Health

Jodi L. Ford

The Ohio State University

Samantha J. Boch

The Ohio State University

Donna O. McCarthy

Marquette University, donnalee.mccarthy@marquette.edu

Accepted version. Nursing Research, Vol. 65, No. 3 (May-June 2016): 249-255. DOI. (C) 2016

Lippincott Williams \& Wilkins, Inc. Used with permission. 


\title{
Feasibility of Hair Collection for Cortisol Measurement in Population Research on Adolescent Health
}

\author{
Jodi L. Ford \\ College of Nursing, Ohio State University, \\ Columbus, $\mathrm{OH}$ \\ Samantha J. Boch \\ College of Nursing, Ohio State University, \\ Columbus, $\mathrm{OH}$ \\ Donna O. McCarthy \\ College of Nursing, Marquette University, \\ Milwaukee, WI
}

\begin{abstract}
Background: Black-White disparities in adolescent health are widespread and thought to be explained, in part, by exposure to chronic stress. Cortisol assayed from hair is increasingly recognized as a valid and reliable measure
\end{abstract}

Nursing Research, Vol 65, No. 3 (May/June 2016): pg. 249-255. DOI. This article is (C) Lippincott Williams \& Wilkins, Inc. and permission has been granted for this version to appear in e-Publications@Marquette. Lippincott Williams \& Wilkins, Inc. does not grant permission for this article to be further copied/distributed or hosted elsewhere without the express permission from Lippincott Williams \& Wilkins, Inc. 
for chronic physiological stress, but the feasibility of collecting hair among large probability samples of diverse adolescents is unknown.

Purpose: The aim of the study was to investigate participation in hair collection for cortisol analyses in a probability sample of racially and socioeconomically diverse adolescents, including the extent to which sociodemographic factors and adverse exposures were associated with participation.

Methods: The study included a probability sample of 516 adolescents conducted in conjunction with a prospective cohort study on adolescent health. Data were collected over 1 week via in-home interviews, ecological momentary assessment, global positioning system methods, and in-home hair collection at the end of the week.

Results: Of the 516 eligible youth, 471 (91.3\%) participated in the hair collection. Of the 45 youth who did not provide hair samples, 18 had insufficient hair, 25 refused, and 2 did not participate for unknown reasons. Multivariable logistic regression results indicated that non-Hispanic Black youth were less likely than their non-Hispanic White peers to participate due to insufficient hair or refusal (OR $=0.24,95 \%$ CI $[0.09,0.60]$ ). Despite lower rates of participation, the proportion of Black youth in the participating sample was representative of the study area. No significant differences in participation were found by other sociodemographic characteristics or adverse exposures.

Conclusions: Hair collection for cortisol measurement is feasible among a probability sample of racially and socioeconomically diverse adolescents. Hair cortisol analyses may accelerate research progress to understand the biological and psychosocial bases of health disparities.

Key Words: adolescent; biomarkers; chronic stress; cortisol; hair; health status disparities; minority groups

Black-White (B/W) disparities in adolescent health are pervasive in the United States (Kitsantas, Kornides, Cantiello, \& Wu, $\underline{2013}$ ), and they often persist across the life course (Harris, GordonLarsen, Chantala, \& Udry, 2006). Chronic physiological stress as a consequence of Blacks' increased exposure to environmental stressors (e.g., poverty, adverse life events, discrimination), in comparison to Whites, is hypothesized to be one of the root causes underlying B/W disparities in health (Williams, 2012). Consequently, studies have increasingly integrated the collection of biomarkers of hypothalamuspituitary-adrenal (HPA) activity (e.g., cortisol) to investigate the extent to which the neuroendocrine pathway explicates the role of chronic stress in shaping racial disparities in health (National Research Council, 2008). and permission has been granted for this version to appear in e-Publications@Marquette. Lippincott Williams \& Wilkins, Inc. does not grant permission for this article to be further copied/distributed or hosted elsewhere without the express permission from Lippincott Williams \& Wilkins, Inc. 
Cortisol is a steroid hormone that is released continuously by the HPA axis into the circulatory system to meet environmental demands (McCarthy, 2012). Under normal conditions, cortisol release follows a circadian rhythm, but levels can increase for a brief period of time when an acute stressor is encountered to ensure adequate glucose is available to the body's cells to respond to the stressor. Once the acute stress response subsides, cortisol levels return to baseline. Conversely, chronic stress occurs when individuals encounter persistent or recurrent external threats to their physical and/or psychological health (Grant et al., 2003), which can cause irregularities in the normal circadian rhythm of cortisol release (Contrada \& Baum, 2011).

To date, prior research examining $\mathrm{B} / \mathrm{W}$ disparities in cortisol levels has focused primarily on collecting saliva to capture the diurnal pattern of cortisol release, which peaks after awakening and reaches its nadir before sleep (McCarthy, 2012). The studies found significant $\mathrm{B} / \mathrm{W}$ disparities in the regulation of the HPA axis, including blunting of the salivary diurnal cortisol curve and elevated salivary basal cortisol levels (DeSantis, Adam, Hawkley, Kudielka, \& Cacioppo, 2015; DeSantis et al., 2007). Although the measurement of cortisol in saliva is particularly useful to capture daily variations in cortisol levels on the diurnal curve, extensive, repeated measurements (or multiple samples) are needed to capture shifts in the normal diurnal rhythm associated with chronic physiological stress (Golden et al., 2014; Hellhammer et al., 2007; Karlamangla, Friedman, Seeman, Stawksi, \& Almeida, 2013). Consequently, cost and high participant burden with multiple sampling protocols often preclude their use, particularly with larger sample sizes (Halpern, Whitsel, Wagner, \& Harris, 2012; Russell, Koren, Rieder, \& Van Uum, 2012).

Hair collected from the posterior vertex region of the scalp has recently been recognized as a useful medium to measure cumulative cortisol levels. Specifically, hair grows approximately $1 \mathrm{~cm}$ a month; thus, the cortisol levels in the $1 \mathrm{~cm}$ of hair most proximate to the root end approximates the mean cortisol level over the preceding month, whereas $3 \mathrm{~cm}$ of hair growth captures mean cortisol for the prior 3 months (Meyer \& Novak, 2012; Russell et al., 2012; Sauvé, Koren, Walsh, Tokmakejian, \& Van Uum, 2007; Stalder \& Kirschbaum, 
2012). The exact mechanism through which cortisol enters the hair shaft is unknown, but experts primarily hypothesize that cortisol is passively diffused from the peripheral vasculature to the follicular cells of the hair shaft, similar to the process for therapeutic drugs and drugs of abuse (Meyer \& Novak, 2012; Pragst \& Balikova, 2006; Russell et al., 2012). Alternatively, cortisol may be diffused into the sebaceous and eccrine glands and secreted along with sebum and sweat onto and perhaps into the hair shaft (Meyer \& Novak, 2012; Raul, Cirimele, Ludes, \& Kintz, 2004; Russell et al., 2012); recent findings indicate mixed support for this hypothesis (Grass et al., 2015; Russell, Koren, Rieder, \& Van Uum, 2014). Last, findings from prior research also suggests that the hair follicle itself may contain a local HPA-like system stimulated by the central HPA system that enables local production and synthesis of cortisol and associated hormones (Arck, Slominski, Theoharides, Peters, \& Paus, 2006; Ito et al., 2005; Meyer \& Novak, 2012; Russell et al., 2012).

Methodological studies have been conducted on the use of hair for cortisol measurement in animals (Davenport, Tiefenbacher, Lutz, Novak, \& Meyer, 2006; Fairbanks et al., 2011) and in humans (Stalder et al., 2012; Vanaelst et al., 2012; Xie et al., 2011), and findings consistently suggest that it is a valid and reliable measure of long-term HPA activity and, thus, chronic physiological stress. However, to date, studies collecting hair for cortisol measurement have been primarily conducted with nonprobability samples in clinical or community settings (e.g., hair salons; Kalmakis, Meyer, Chiodo, \& Leung, 2015; O'Brien, Tronick, \& Moore, 2013; Staufenbiel, Penninx, Spijker, Elzinga, \& van Rossum, 2013; Steudte et al., 2013; Wosu et al., 2015), which can increase selection bias and reduce generalizability of findings. In addition, most research has focused on adults, and there has been limited representation of racial and ethnic minorities, including Black participants-a population found in prior research to be more likely to refuse participation in health research and biomarker collection due to mistrust of researchers over prior research misconduct and fear of discrimination (George, Duran, \& Norris, 2014). Some participants may also be unwilling or unable to have their hair cut for research. For example, both male and female participants may have no hair or very short hair that either precludes their participation or makes cutting more difficult. In addition, others may have hairstyles that require them to be undone prior to cutting 
(e.g., extensions or braids) or they may take a long time to grow (e.g., dreadlocks or very long hair) - both of which could reduce participation. Because adolescents are more likely to place a greater emphasis on their appearance than any other stage of development and their hairstyle is often associated with their identity (Kerig, Schulz, \& Hauser, 2012), their willingness to have their hair cut could be affected. However, the impact of this on stress research utilizing hair collection, particularly among adolescents, is difficult to ascertain due to prior reliance on convenience sampling.

To address the aforementioned limitations, the purpose of this study was to test the feasibility of collecting hair for cortisol measurement from a probability subsample of 516 racially and socioeconomically diverse urban adolescents aged 11-17 years participating in a larger prospective cohort study on adolescent health and well-being. Specifically, to what extent does hair length and refusal to have hair cut affect the participation rate in hair collection research utilizing a probability sample of adolescents? Differences between participants (those who provided hair samples) and nonparticipants with respect to sociodemographic factors and adverse exposures were also examined, as prior research has found both to be associated with research participation (Bender, Kawachi, Jørgensen, \& Pisinger, 2015; Storr, Or, Eaton, \& Ialongo, 2014) and cortisol levels in hair (Kalmakis et al., 2015; Karlén et al., 2015; Staufenbiel et al., 2013; Wosu et al., 2015). The findings of this study will provide insight into the feasibility of employing this novel data collection technique in larger epidemiological studies with probability samples of diverse adolescents that can then advance our understanding of the contribution of chronic physiological stress to racial disparities in adolescent health.

\section{Methods}

\section{Design}

The study leverages data from two ongoing studies:

1. The Adolescent Health and Development in Context (AHDC) study-A prospective cohort study that examines the impact of activity space exposures on the behavioral and health outcomes of a probability sample of youth aged 11-17 years in Franklin County, Ohio. 
2. The Linking Biological and Social Pathways to Adolescent Health and Wellbeing study (Bio-Social Linkages)-A probability subsample of 516 youth who participated in the first wave of the AHDC study in which chronic stress biomarkers, including hair for cortisol measurement, were collected for linkage to the AHDC study.

\section{Sample and Data Collection}

The study takes place in Franklin County, Ohio-a large, metropolitan area with an estimated 2012 population of 1.2 million (U.S. Census Bureau, 2015). Franklin County contains the city of Columbus, which is representative of the average U.S. metropolitan area in terms of social and economic characteristics. The study area incorporates Columbus and the suburban municipalities that border or are contained within the boundaries of Columbus for comparisons between youth residing in low-income, urban neighborhoods and those residing in the highest-income, suburban locations. The subsample characteristics are relatively comparable to those of the study area with respect to median household income and racial and ethnic composition.

The sampling frame was based on a combination of a vendorprovided list of eligible households and public school data from the study area. The addresses were sorted by zip code, and random replicates of 500 participants were drawn. Households within selected replicates were mailed a letter or postcard describing the study, followed by interviewer calls to the household to solicit participation in the study. Among contacted, eligible households, one randomly selected youth aged 11-17 years and one primary caregiver (both English speaking) were recruited to participate in the study. The interviewer discussed the biomarker collection with the primary caregiver on the phone. Primary caregivers were asked about their child's use of corticosteroids in the prior month; youth who had taken corticosteroids in the past month were ineligible for the biomarker collection due to the impact of the medication on cortisol levels ( $\mathrm{n}=$ 10; Granger, Hibel, Fortunato, \& Kapelewski, 2009).

The AHDC study collects two waves of data, approximately 1 year apart. Within each wave, data are collected over a weeklong period via in-home interviewing of the focal youth and his or her primary caregiver on Days 1 and 7 along with a 7-day, smartphonebased global positioning system tracking and ecological momentary 
assessment data collection period of the youth. During the first home visit, the interviewer discussed the hair collection again in the household with the primary caregiver and the youth. Youth or caregivers who refused participation and youth with insufficient hair length to cut $(<1 \mathrm{~cm})$ were categorized as nonparticipants in the hair collection, but they remained participants in the parent AHDC study (as did youth on corticosteroids). Parental permission and youth assent were obtained prior to hair collection on the second home visit. To collect the hair, trained interviewers cut approximately 10-50 mg of hair $(0.4-1 \mathrm{~cm}$ in diameter) from the posterior vertex region of the youth's scalp using a new pair of thinning shears, which minimize the visibility that the hair was cut (Hoffman, Karban, Benitez, Goodteacher, \& Laudenslager, 2014). The posterior vertex region of the scalp is the preferred area for sampling as cortisol levels vary less in hair collected from this region in comparison to others (Sauvé et al., 2007). Adolescents were compensated $\$ 20$ for their participation in the hair collection.

\section{Measures}

Participation in hair collection was coded as a dichotomous measure to compare youth who participated in the hair collection and provided a hair sample ( $1=$ yes; $0=$ no) to those who did not participate due to refusal or insufficient hair for cutting $(<1 \mathrm{~cm})$. The small sample size of youth who did not participate in the hair collection due to insufficient hair $(n=18)$ or who refused $(n=25)$ precluded a more refined multinomial measure except for exploratory analyses.

Sociodemographic factors included race and ethnicity (nonHispanic White, non-Hispanic Black, "other"), biological sex ( $1=$ male; 0 = female), age (continuous measure), and caregiver education (high school or less, bachelor's degree, master's degree, doctoral or professional degree). The Bio-Social Linkages study did collect hair on adolescent participants who self-identified as Hispanic/Latino ( $n=27 ; 5.2 \%)$, non-Hispanic Asian ( $n=8 ; 1.6 \%)$, non-Hispanic multiracial ( $\mathrm{n}=32 ; 6.2 \%)$, and non-Hispanic "other" ( $\mathrm{n}$ $=8 ; 1.6 \%$ ), but they were collapsed into an "other" category as only five of the participants (two Hispanic/Latino and three multiracial participants) across these racial and ethnic categories did not 
participate in the hair collection. Thus, the cell sizes were too small for reliable estimation.

Adverse childhood experiences was a count of the youth's total lifetime exposures to the following events as reported by the primary caregiver: mother died, father died, sibling died, parent incarcerated, sibling incarcerated, parents divorced, child witnessed household or neighborhood violence, child a victim of household or neighborhood violence, child was homeless/lived in a homeless shelter or hotel, or child moved into foster care. The items included in the checklist were adapted from prior research on adverse childhood experiences (Felitti et al., 1998; Finkelhor, Shattuck, Turner, \& Hamby, 2015).

Activity space exposures to socioeconomic adversity was based on youths' activity space, which consisted of all of the locations that individuals come into contact with as a result of their routine activities to better capture the breadth of their social and spatial exposures (Browning \& Soller, 2014; Kwan, 2009). Activity space measures were calculated using the global positioning system tracking data that were geocoded to census block group and linked with 2009-2013 American Community Survey data. Two activity space measures were calculated: (a) activity space exposure to poverty was a dichotomous measure of youths' mean exposure to activity space family poverty rates greater than or equal to $25 \%$ and (b) activity space exposure to vacant housing was a dichotomous measure of youths' mean exposure to activity space residential vacancy rates greater than or equal to $15 \%$. These measures were dichotomized based on the distribution of the sample and represent the top $25 \%$ of the distribution. The measures were also analyzed as continuous variables, and the results between measurement approaches were consistent.

\section{Analytic Strategy}

Descriptive analyses were conducted, stratified by participation to compare adolescents who participated in the hair collection to those who had insufficient hair or refused to participate. Bivariate and multivariable logistic regression analyses were then conducted to investigate the differences in sociodemographic characteristics and exposure to adverse childhood events and socioeconomically disadvantaged activity spaces between youth who participated in the hair collection to those who did not. A total of 80 youth were missing 
data on one or more of the following measures: adverse childhood events, activity space poverty, and activity space vacant housing. Multiple imputation of missing data was conducted; results were consistent with a complete case approach to missing data; thus, we present the results for the latter approach.

\section{Results}

Of the 516 adolescents aged $11-17$ years eligible to participate in the study (no corticosteroid use), 471 (91.3\%) provided hair samples for cortisol assay. Of the 45 youth who did not participate in the hair collection, 18 adolescents had insufficient hair, 25 adolescents or caregivers refused, and 2 adolescents did not participate for unknown reasons. The reasons for refusal, if given, were concerns over privacy or the collection of biomaterial $(n=6)$, did not want to be touched $(n=3)$, or did not want to have hair cut due to extensions or braids ( $n=3$ non-Hispanic Black female participants).

Bivariable logistic regression analyses (Table 1) indicated that non-Hispanic Black youth were less likely than non-Hispanic White youth to participate in the hair collection due to insufficient hair/refusal $(\mathrm{OR}=0.26 ; 95 \% \mathrm{CI}[0.13,0.51])$. Although the individual cell sizes were small, we conducted post hoc, multinomial, bivariable regression analyses to explore the racial and ethnic differences between youth who had insufficient hair $(n=18)$ or refused participation ( $n=25$ ) to those youth who participated in the hair collection ( $n=471$ ). The findings indicated that non-Hispanic Black youth were more likely to have insufficient hair $(\mathrm{OR}=8.83$; $95 \%$ CI $[2.47,31.53])$ and refuse participation (OR $=2.45 ; 95 \% \mathrm{CI}$ $[1.03,5.81])$ in comparison to their non-Hispanic White peers (results not depicted in table, but available upon request). Bivariable regressions found no significant differences in participation with respect to "other" race and ethnicity (vs. non-Hispanic White), age, sex, parental level of education, household income, number of adverse childhood events experienced, or activity space measures of socioeconomic adversity. Multivariable logistic regression results were consistent with the bivariable analyses (see Table 2). Specifically, non-Hispanic Black youth were less likely to participate in the hair collection due to insufficient hair/refusal in comparison to nonHispanic White youth (adjusted OR $=0.24 ; 95 \%$ CI $[0.09,0.60]$ ). No 
significant differences in participation were found with respect to other sociodemographic characteristics, adverse childhood events experienced, or activity space measures of socioeconomic adversity.

\section{Discussion}

The findings of our study indicate a high participation rate at $91 \%$ for the collection of hair for cortisol measurement in a large probability sample of racially and socioeconomically diverse adolescents. Design features of our study that most likely facilitated participation include the collection of hair samples from participants in their homes by trained interviewers and the need for only a one-time collection, both of which may have reduced respondent burden. In addition, we used thinning shears (Hoffman et al., 2014) versus regular scissors to minimize the visibility that the hair was cut. Although the use of thinning shears required more training and skill for sufficient amounts of hair to be obtained, the interviewers collectively reported that their use enhanced participation, particularly among female participants.

Although our study had high participation rates in the hair sample collection overall, non-Hispanic Black adolescents were less likely than their non-Hispanic White peers to participate in the hair collection due to insufficient hair or refusal of participation. No significant differences were found between adolescents who did and did not participate in the hair collection by age, sex, exposure to adverse childhood events, or socioeconomic adversity. Researchers may need to consider oversampling Black participants (and male participants in particular) if a high proportion of their study sample has too short of hair for cutting. Only three of the non-Hispanic Black female adolescents refused to participate due to extensions or braids, and interviewers reported many youth were willing to undo their braids or remove extensions for the hair collection. With respect to refusals of participation, our findings are consistent with prior investigations on minority participation in clinical trials (Chen, Lara, Dang, Paterniti, \& Kelly, 2014) and storage of biospecimens for future research (Storr et al., 2014). Mistrust of researchers and the integrity of the research process have been reported across the literature as reasons for nonparticipation among minority populations (George et al., 2014). Our study design incorporated many of the recommendations to facilitate minority participation (George et al., 
2014), including safety assurances that caregivers and youth could withdraw from the research at any time without penalty. In addition, we used the same interviewer when possible for recruitment and data collection to enhance familiarity and build trust. Furthermore, we had separate consents for each aspect of the data collection, so participants could choose to opt out of the collection of the hair and/or saliva biomarkers and still participate in the AHDC study. Last, our consent forms reinforced that only cortisol would be assayed from the hair and any remaining specimens would be discarded.

Hair has significant meaning across and within cultures and subcultures.

Despite the increased likelihood of nonparticipation among nonHispanic Black youth in the hair collection, they still comprised $28 \%$ ( $n=132$ ) of the final participating sample-a proportion consistent with the population distribution in the study area. Although the proportion of other racial and ethnic groups (e.g., Latino/Hispanic, Asian) in our study was also relatively comparable to the overall study area, the smaller cell sizes precluded reliable estimation of differences between and within these racial and ethnic groups. Thus, researchers should consider oversampling underrepresented racial and ethnic populations within their communities as needed to determine the feasibility of collecting hair in these populations. Researchers should take into consideration in their study design potential cultural, political, and religious or spiritual preferences that may preclude or reduce participation. For example, prior research investigating levels of methylmercury in hair have reported low uptake of hair collection among American Indian and Alaska Native communities (Knobeloch, Anderson, Imm, Peters, \& Smith, 2005; Kuntz, Hill, Linkenbach, Lande, \& Larsson, 2009). Among many American Indian and Alaska Native persons, hair is culturally and spiritually significant with hair cutting generally conducted only under certain circumstances (e.g., mourning periods). Furthermore, the historical trauma of forced hair cutting and continued discrimination over men wearing their hair long (Evans-Campbell, 2008; Treuer, 2012) may decrease participation in hair collection studies. Although not every American Indian and Alaska Native person will refuse hair cutting, researchers must practice cultural safety throughout the research process (McCleland, 2011; Priscilla, 2002) and recognize that hair has significant meaning 
across and within cultures and subcultures. Furthermore, as discussed previously, prior research misconduct has contributed to mistrust of researchers and could affect willingness to participate in research overall and, in particular, the collection of biospecimens. Thus, researchers should consider incorporating the recommendations to facilitate minority participation in their study design as outlined above (George et al., 2014), as well as engaging with communities throughout the research process.

This study is among the first to explore the feasibility of collecting hair samples for cortisol in a probability sample of racially and socioeconomically diverse urban adolescents. The findings provide evidence that the collection of hair for the measurement of long-term HPA activity via mean cortisol levels is feasible and can be integrated into large population studies investigating the contribution of chronic stress to adolescent health and racial and socioeconomic health disparities. Research linking complex social and biological pathways to health is needed to elucidate new avenues for intervention and, ultimately, the prevention of racial and socioeconomic disparities in adolescent health.

\section{References}

Arck P. C., Slominski A., Theoharides T. C., Peters E. M. J., Paus R. (2006). Neuroimmunology of stress: Skin takes center stage. Journal of Investigative Dermatology, 126, 1697-1704. doi:10.1038/sj.jid.5700104

Bender A. M., Kawachi I., Jørgensen T., Pisinger C. (2015). Neighborhood deprivation is strongly associated with participation in a populationbased health check. PLOS ONE, 10, e0129819. doi:10.1371/journal.pone.0129819

Browning C. R., Soller B. (2014). Moving beyond neighborhood: Activity spaces and ecological networks as contexts for youth development. Cityscape, 16, 165-196.

Chen M. S. Jr., Lara P. N., Dang J. H. T., Paterniti D. A., Kelly K. (2014). Twenty years post-NIH Revitalization Act: Enhancing minority participation in clinical trials (EMPaCT): Laying the groundwork for improving minority clinical trial accrual. Cancer, 120, 1091-1096. doi:10.1002/cncr.28575

Contrada R. J., Baum A. (Eds.). (2011). The handbook of stress science: Biology, psychology, and health. New York, NY: Springer. 
Davenport M. D., Tiefenbacher S., Lutz C. K., Novak M. A., Meyer J. S. (2006). Analysis of endogenous cortisol concentrations in the hair of rhesus macaques. General and Comparative Endocrinology, 147, 255-261. doi:10.1016/j.ygcen.2006.01.005

DeSantis A. S., Adam E. K., Doane L. D., Mineka S., Zinbarg R. E., Craske M. G. (2007). Racial/ethnic differences in cortisol diurnal rhythms in a community sample of adolescents. Journal of Adolescent Health, 41, 3-13. doi:10.1016/j.jadohealth.2007.03.006

DeSantis A. S., Adam E. K., Hawkley L. C., Kudielka B. M., Cacioppo J. T. (2015). Racial and ethnic differences in diurnal cortisol rhythms: Are they consistent over time? Psychosomatic Medicine, 77, 6-15. doi: $10.1097 /$ psy.0000000000000131

Evans-Campbell T. (2008). Historical trauma in American Indian/Native Alaska communities: A multilevel framework for exploring impacts on individuals, families, and communities. Journal of Interpersonal Violence, 23, 316-338. doi:10.1177/0886260507312290.

Fairbanks L. A., Jorgensen M. J., Bailey J. N., Breidenthal S. E., Grzywa R., Laudenslager M. L. (2011). Heritability and genetic correlation of hair cortisol in vervet monkeys in low and higher stress environments. Psychoneuroendocrinology, 36, 1201-1208. doi:10.1016/j.psyneuen.2011.02.013

Felitti V. J., Anda R. F., Nordenberg D., Williamson D. F., Spitz A. M., Edwards V., Marks J. S. (1998). Relationship of childhood abuse and household dysfunction to many of the leading causes of death in adults. The Adverse Childhood Experiences (ACE) Study. American Journal of Preventive Medicine, 14, 245-258. doi:10.1016/S07493797(98)00017-8

Finkelhor D., Shattuck A., Turner H., Hamby S. (2015). A revised inventory of adverse childhood experiences. Child Abuse \& Neglect, 48, 13-21. doi: $10.1016 /$ j.chiabu.2015.07.011

George S., Duran N., Norris K. (2014). A systematic review of barriers and facilitators to minority research participation among African Americans, Latinos, Asian Americans, and Pacific Islanders. American Journal of Public Health, 104, e16-e31. doi:10.2105/ajph.2013.301706

Golden S. H., Sánchez B. N., DeSantis A. S., Wu M., Castro C., Seeman T. E., Roux A. V. D. (2014). Salivary cortisol protocol adherence and reliability by socio-demographic features: The Multi-Ethnic Study of Atherosclerosis. Psychoneuroendocrinology, 43, 30-40- . doi:10.1016/j.psyneuen.2014.01.025

Nursing Research, Vol 65, No. 3 (May/June 2016): pg. 249-255. DOI. This article is (C) Lippincott Williams \& Wilkins, Inc. and permission has been granted for this version to appear in e-Publications@Marquette. Lippincott Williams \& Wilkins, Inc. does not grant permission for this article to be further copied/distributed or hosted elsewhere without the express permission from Lippincott Williams \& Wilkins, Inc. 
Granger D. A., Hibel L. C., Fortunato C. K., Kapelewski C. H. (2009). Medication effects on salivary cortisol: Tactics and strategy to minimize impact in behavioral and developmental science. Psychoneuroendocrinology, 34, 1437-1448. doi:10.1016/j.psyneuen.2009.06.017

Grant K. E., Compas B. E., Stuhlmacher A. F., Thurm A. E., McMahon S. D., Halpert J. A. (2003). Stressors and child and adolescent psychopathology: Moving from markers to mechanisms of risk. Psychological Bulletin, 129, 447-466. doi:10.1037/00332909.129.3.447

Grass J., Kirschbaum C., Miller R., Gao W., Steudte-Schmiedgen S., Stalder T. (2015). Sweat-inducing physiological challenges do not result in acute changes in hair cortisol concentrations. Psychoneuroendocrinology, 53, 108-116. doi:10.1016/j.psyneuen.2015.07.565

Halpern C. T., Whitsel E. A., Wagner B., Harris K. M. (2012). Challenges of measuring diurnal cortisol concentrations in a large population-based field study. Psychoneuroendocrinology, 37, 499-508. doi: 10.1016/j.psyneuen.2011.07.019

Harris K. M., Gordon-Larsen P., Chantala K., Udry J. R. (2006). Longitudinal trends in race/ethnic disparities in leading health indicators from adolescence to young adulthood. Archives of Pediatric \& Adolescent Medicine, 160, 74-81. doi:10.1001/archpedi.160.1.74

Hellhammer J., Fries E., Schweisthal O. W., Schlotz W., Stone A. A., Hagemann D. (2007). Several daily measurements are necessary to reliably assess the cortisol rise after awakening: State- and trait components. Psychoneuroendocrinology, 32, 80-86. doi:10.1016/j.psyneuen.2006.10.005

Hoffman M. C., Karban L. V., Benitez P., Goodteacher A., Laudenslager M. L. (2014). Chemical processing and shampooing impact cortisol measured in human hair. Clinical and Investigative Medicine, 37, E252-E257. http://cimonline.ca/index.php/cim/article/view/21731/17663

Ito N., Ito T., Kromminga A., Bettermann A., Takigawa M., Kees F., Paus R. (2005). Human hair follicles display a functional equivalent of the hypothalamic-pituitary-adrenal axis and synthesize cortisol. FASEB Journal, 19, 1332-1334. doi:10.1096/fj.04-1968fje

Kalmakis K. A., Meyer J. S., Chiodo L., Leung K. (2015). Adverse childhood experiences and chronic hypothalamic-pituitary-adrenal activity. Stress, 18, 446-450. doi:10.3109/10253890.2015.1023791

Nursing Research, Vol 65, No. 3 (May/June 2016): pg. 249-255. DOI. This article is (C) Lippincott Williams \& Wilkins, Inc. and permission has been granted for this version to appear in e-Publications@Marquette. Lippincott Williams \& Wilkins, Inc. does not grant permission for this article to be further copied/distributed or hosted elsewhere without the express permission from Lippincott Williams \& Wilkins, Inc. 
Karlamangla A. S., Friedman E. M., Seeman T. E., Stawksi R. S., Almeida D. M. (2013). Daytime trajectories of cortisol: Demographic and socioeconomic differences-Findings from the National Study of Daily Experiences. Psychoneuroendocrinology, 38, 2585-2597. doi:10.1016/j.psyneuen.2013.06.010

Karlén J., Ludvigsson J., Hedmark M., Faresjö A., Theodorsson E., Faresjö T. (2015). Early psychosocial exposures, hair cortisol levels, and disease risk. Pediatrics. doi:10.1542/peds.2014-2561

Kerig P. K., Schulz M. S., Hauser S. T. (Eds.) (2012). Adolescence and beyond: Family processes and development. New York, NY: Oxford University Press.

Kitsantas P., Kornides M. L., Cantiello J., Wu H. (2013). Chronic physical health conditions among children of different racial/ethnic backgrounds. Public Health, 127, 546-553. doi:10.1016/j.puhe.2013.02.006

Knobeloch L., Anderson H. A., Imm P., Peters D., Smith A. (2005). Fish consumption, advisory awareness, and hair mercury levels among women of childbearing age. Environmental Research, 97, 220-227. doi: 10.1016/j.envres.2004.07.001

Kuntz S. W., Hill W. G., Linkenbach J. W., Lande G., Larsson L. (2009). Methylmercury risk and awareness among American Indian women of childbearing age living on an inland northwest reservation. Environmental Research, 109, 753-759. doi:10.1016/j.envres.2009.04.007

Kwan M. P. (2009). From place-based to people-based exposure measures. Social Science \& Medicine, 69, 1311-1313. doi: $10.1016 /$ j.socscimed.2009.07.013

McCarthy D. (2012). Biological measurement in intervention research. In Melnyk B. M., Morrison-Beedy D. (Eds.), Intervention research: Designing, conducting, analyzing and funding (pp. 135-148). New York, NY: Springer.

McCleland A. (2011). Culturally safe nursing research: Exploring the use of an indigenous research methodology from an indigenous researcher's perspective. Journal of Transcultural Nursing, 22, 362-367. doi: $10.1177 / 1043659611414141$

Meyer J. S., Novak M. A. (2012). Minireview: Hair cortisol: A novel biomarker of hypothalamic-pituitary-adrenocortical activity. Endocrinology, 153, 4120-4127. doi:10.1210/en.2012-1226

National Research Council. (2008). Biosocial surveys: National Research Council (US) Committee on advances in collecting and utilizing

Nursing Research, Vol 65, No. 3 (May/June 2016): pg. 249-255. DOI. This article is (C Lippincott Williams \& Wilkins, Inc. and permission has been granted for this version to appear in e-Publications@Marquette. Lippincott Williams \& Wilkins, Inc. does not grant permission for this article to be further copied/distributed or hosted elsewhere without the express permission from Lippincott Williams \& Wilkins, Inc. 
NOT THE PUBLISHED VERSION; this is the author's final, peer-reviewed manuscript. The published version may be accessed by following the link in the citation at the bottom of the page.

biological indicators and genetic information in social science surveys. Washington, DC: National Academies Press.

O'Brien K. M., Tronick E. Z., Moore C. L. (2013). Relationship between hair cortisol and perceived chronic stress in a diverse sample. Stress and Health, 29, 337-344. doi:10.1002/smi.2475

Pragst F., Balikova M. A. (2006). State of the art in hair analysis for detection of drug and alcohol abuse. Clinical Chimica Acta, 370, 1749. doi:10.1016/j.cca.2006.02.019

Priscilla P. (2002). Towards reconciliation in indigenous health research: The responsibilities of the non-indigenous researcher. Contemporary Nurse, 14, 56-65. doi:10.5172/conu.14.1.56

Raul J. S., Cirimele V., Ludes B., Kintz P. (2004). Detection of physiological concentrations of cortisol and cortisone in human hair. Clinical Biochemistry, 37, 1105-1111. doi:10.1016/j.clinbiochem.2004.02.010

Russell E., Koren G., Rieder M., Van Uum S. (2012). Hair cortisol as a biological marker of chronic stress: Current status, future directions and unanswered questions. Psychoneuroendocrinology, 37, 589-601. doi:10.1016/j.psyneuen.2011.09.009

Russell E., Koren G., Rieder M., Van Uum S. H. (2014). The detection of cortisol in human sweat: Implications for measurement of cortisol in hair. Therapeutic Drug Monitoring, 36, 30-34. doi:10.1097/FTD.0b013e31829daa0a

Sauvé B., Koren G., Walsh G., Tokmakejian S., Van Uum S. H. (2007). Measurement of cortisol in human hair as a biomarker of systemic exposure. Clinical and Investigative Medicine, 30, E183-E191.

Retrieved from http://cimonline.ca/index.php/cim/article/view/2894/1049

Stalder T., Kirschbaum C. (2012). Analysis of cortisol in hair-State of the art and future directions. Brain, Behavior, and Immunity, 26, 1019-1029. doi:10.1016/j.bbi.2012.02.002

Stalder T., Steudte S., Miller R., Skoluda N., Dettenborn L., Kirschbaum C. (2012). Intraindividual stability of hair cortisol concentrations. Psychoneuroendocrinology, 37, 602-610. doi:10.1016/j.psyneuen.2011.08.007

Staufenbiel S. M., Penninx B. W., Spijker A. T., Elzinga B. M., van Rossum E. F. (2013). Hair cortisol, stress exposure, and mental health in humans: A systematic review. Psychoneuroendocrinology, 38, 12201235. doi: 10.1016/j.psyneuen.2012.11.015

Nursing Research, Vol 65, No. 3 (May/June 2016): pg. 249-255. DOI. This article is (c) Lippincott Williams \& Wilkins, Inc. and permission has been granted for this version to appear in e-Publications@Marquette. Lippincott Williams \& Wilkins, Inc. does not grant permission for this article to be further copied/distributed or hosted elsewhere without the express permission from Lippincott Williams \& Wilkins, Inc. 
Steudte S., Kirschbaum C., Gao W., Alexander N., Schönfeld S., Hoyer J., Stalder T. (2013). Hair cortisol as a biomarker of traumatization in healthy individuals and posttraumatic stress disorder patients. Biological Psychiatry, 74, 639-646. doi: $10.1016 /$ j.biopsych.2013.03.011

Storr C. L., Or F., Eaton W. W., Ialongo N. (2014). Genetic research participation in a young adult community sample. Journal of Community Genetics, 5, 363-375. doi:10.1007/s12687-014-0191-3

Treuer A. (2012). Everything you wanted to know about Indians but were afraid to ask. St. Paul, MN: Minnesota Historical Society Press/Borealis Books.

U.S. Census Bureau. (2015). QuickFacts: Franklin County, OH. Retrieved from http://quickfacts.census.gov/qfd/states/39/39049.html

Vanaelst B., Huybrechts I., Bammann K., Michels N., de Vriendt T., Vyncke K., de Henauw S. (2012). Intercorrelations between serum, salivary, and hair cortisol and child-reported estimates of stress in elementary school girls. Psychophysiology, 49, 1072-1081. doi:10.1111/j.14698986.2012.01396.x

Williams D. R. (2012). Miles to go before we sleep: Racial inequities in health. Journal of Health and Social Behavior, 53, 279-295. doi: $10.1177 / 0022146512455804$

Wosu A. C., Gelaye B., Valdimarsdóttir U., Kirschbaum C., Stalder T., Shields A. E., Williams M. A. (2015). Hair cortisol in relation to sociodemographic and lifestyle characteristics in a multiethnic US sample. Annals of Epidemiology, 25, 90-95. doi: $10.1016 /$ j.annepidem.2014.11.022

Xie Q., Gao W., Li J., Qiao T., Jin J., Deng H., Lu Z. (2011). Correlation of cortisol in $1-\mathrm{cm}$ hair segment with salivary cortisol in human: Hair cortisol as an endogenous biomarker. Clinical Chemistry and Laboratory Medicine, 49, 2013-2019. doi:10.1515/cclm.2011.706

The authors would like to thank Dr. Mark Laudenslager for his generosity in sharing data collection tools, The Ohio State University Center for Human Resource Research project team, and the adolescents and families who participated in the study.

The authors acknowledge that this study was funded by National Institutes of Health, National Institute on Drug Abuse (1R21DA034960 and 1R01DA032371), and National Institute of Child Health and Development (2P2CHD058484).

The authors have no conflicts of interest to declare. and permission has been granted for this version to appear in e-Publications@Marquette. Lippincott Williams \& Wilkins, Inc. does not grant permission for this article to be further copied/distributed or hosted elsewhere without the express permission from Lippincott Williams \& Wilkins, Inc. 
NOT THE PUBLISHED VERSION; this is the author's final, peer-reviewed manuscript. The published version may be accessed by following the link in the citation at the bottom of the page.

\section{Corresponding author: Jodi L. Ford, PhD, RN, The Ohio State University College of Nursing, 1585 Neil Ave., Columbus, OH 43210 (e-mail: ford.553@osu.edu).}

Table 1.

\begin{tabular}{|c|c|c|c|c|c|c|c|}
\hline \multirow[b]{2}{*}{ Characteristic } & \multirow[b]{2}{*}{$n$} & \multicolumn{2}{|c|}{ Participant } & \multicolumn{2}{|c|}{ Nonparticipant } & \multirow[b]{2}{*}{$O R$} & \multirow[b]{2}{*}{$95 \% \mathrm{Cl}$} \\
\hline & & $n$ & $(\%)^{a}$ & $n$ & $(\%)^{a}$ & & \\
\hline Sex & 516 & & & & & & \\
\hline Male & & 237 & $(89.1)$ & 29 & $(109)$ & 0.56 & {$[0.30,1.06]$} \\
\hline Female (reference) & & 234 & 93.6 & 16 & 6.4 & & \\
\hline Racelethnicity & 516 & & & & & & \\
\hline NH Black & & 132 & $(83.5)$ & 26 & (16.5) & $0.26^{*} *$ & {$[0.13,0.51]$} \\
\hline Other & & 70 & $\{93.3\}$ & 5 & $(6,7)$ & 0.73 & {$[0.25,2.09]$} \\
\hline NH White (feference) & & 269 & (95.1) & 14 & $(4.9)$ & & \\
\hline Caregiver education & 510 & & & & & & \\
\hline$\leq$ HS diploma & & 79 & (89.8) & 9 & $(10.2)$ & 0.73 & {$[0.28,1.93]$} \\
\hline Some college & & 148 & $(89.7)$ & 17 & $(10.3)$ & 0.73 & {$[0.31,1.69]$} \\
\hline Bachelor's degree & & 130 & (92.9) & 10 & (7.1) & 1.08 & {$[0.43,2.76]$} \\
\hline \multirow[t]{2}{*}{$\geq$ Master's degree (reference) } & & 108 & (92.3) & 9 & $(7,7)$ & & \\
\hline & & $M$ & $(S D)$ & $M$ & $(S D)$ & & \\
\hline Age (years) & 516 & 14.60 & (1.79) & 14.47 & $(1.77)$ & 1.04 & {$[0.88,1.24]$} \\
\hline $\mathrm{ACE}$ (range 0-11) & 476 & 0.68 & $(1.47)$ & 0.78 & $(1.46)$ & 0.96 & $10.78,1.171$ \\
\hline AS poverty ( $\geq 25 \%$ ) & 474 & 0.22 & $(0.41)$ & 0.29 & $\langle 0.46\rangle$ & 0.70 & {$[0.35,1.38]$} \\
\hline AS vacant housing $(\geq 15 \%)$ & 474 & 0.28 & (0.45) & 0.38 & $\langle 0,49\rangle$ & 0.63 & {$[0.31,1.26]$} \\
\hline
\end{tabular}

Note $\mathrm{ACE}=$ adverse childhoad events, $\mathrm{AS}=$ activity space; $\mathrm{CI}=$ confidence intervat, $\mathrm{HS}=$ high school; $O R=$ odds ratio (unadjusted); $\mathrm{NH}=$ non-Hispanic. "Row percentages are shown. ${ }^{*+*} p<.001$.

Nursing Research, Vol 65, No. 3 (May/June 2016): pg. 249-255. DOI. This article is (C) Lippincott Williams \& Wilkins, Inc. and permission has been granted for this version to appear in e-Publications@Marquette. Lippincott Williams \& Wilkins, Inc. does not grant permission for this article to be further copied/distributed or hosted elsewhere without the express permission from Lippincott Williams \& Wilkins, Inc. 
NOT THE PUBLISHED VERSION; this is the author's final, peer-reviewed manuscript. The published version may be accessed by following the link in the citation at the bottom of the page.

\section{Table 2.}

\begin{tabular}{llr}
\hline Predictor & AOR & {$[95 \%$ CI] } \\
\hline Age & 0.99 & {$[0.81,1.21]$} \\
Sex (male) & 0.59 & {$[0.29,1.21]$} \\
Race/ethnicity & & \\
$\quad$ NH Black & $0.24^{* *}$ & {$[0.09,0.60]$} \\
$\quad$ Other & 0.80 & {$[0.24,2.62]$} \\
$\quad$ NH White (reference) & 1.00 & \\
Caregiver education & & \\
$\quad$ SHS diploma & 1.09 & {$[0.34,3.51]$} \\
$\quad$ Some college & 1.16 & {$[0.41,3.30]$} \\
$\quad$ Bachelor's degree & 1.11 & {$[0.38,3.22]$} \\
$\quad$ Master's degree (reference) & 1.00 & \\
ACE (range 0-11) & 1.06 & {$[0.81,1.38]$} \\
AS poverty ( $\geq 25 \%)$ & 0.94 & {$[0.37,2.32]$} \\
AS vacant housing ( $\geq 15 \%)$ & 1.18 & {$[0.49,2.83]$} \\
\hline
\end{tabular}

Note. $n=436$. Models were estimated using multiple imputation of missing data and with listwise deletion; results were similar; the model estimated using listwise deletion is shown. $A C E=$ adverse childhood events; $A O R=$ adjusted odds ratio; $\mathrm{AS}=$ activity space; $\mathrm{Cl}=$ confidence interval; $\mathrm{NH}=$ non-Hispanic. ${ }^{* *} p<01$.

Nursing Research, Vol 65, No. 3 (May/June 2016): pg. 249-255. DOI. This article is (C Lippincott Williams \& Wilkins, Inc. and permission has been granted for this version to appear in e-Publications@Marquette. Lippincott Williams \& Wilkins, Inc. does not grant permission for this article to be further copied/distributed or hosted elsewhere without the express permission from Lippincott Williams \& Wilkins, Inc. 